\title{
Gerontological Issues in Bengali Film Dekha
}

\author{
Ashoke Kumar Mandal ${ }^{1} \&$ Dr. Shrikrishan Rai ${ }^{2}$ \\ ${ }^{1}$ Research Scholar, Department of Humanities and Social Sciences, National Institute of \\ Technology, Durgapur, India. Email: akmandalıoo@gmail. \\ ${ }^{2}$ Associate Professor, Department of Humanities and Social Sciences, National Institute of \\ Technology, Durgapur, India.
}

First published September 30, 2019

\begin{abstract}
In the Indian context modernization, industrialization, urbanization, and westernization-'the four horsemen of the modern apocalypse' (Laurence Cohen, 1998:p.17) have a significant predicament in recent dimensions of gerontology. The problem relates to population ageing, controlled fertility, mortality rates and eventually the increase of life expectancy. The proliferation of old age home, extensive overseas migration, transnational dispersal of families, dissociation of the traditional multigenerational joint family, and simultaneous rise up of the nuclear family etc., are also some major causes behind the problems. These multidimensional interrelated challenges have been artistically shown in case of some old characters in Gautam Ghosh's national award-winning Bengali film Dekha (2001). Particularly in the life of the protagonist, Sashibhusan Sanyal the problems have found differently added significance because of his disability (blindness).But his positive attitude to fight against the oddities of life contextualizes the film with a projection to highlight the old age problems from three main foci-biological, psychological, and social, to justify the relevance of the problematic. This paper argues the necessity of a consolidated progressive action by social scientists, policy makers and the elderly community to promote healthy and fruitful ageing at all spheres to counter the old age hazards.
\end{abstract}

Keywords: gerontology, population ageing, urbanization, loneliness, social exclusion.

\section{Introduction}

Ageing is a process that encompasses a broad spectrum of experiences. The $21^{\text {st }}$ century has been witnessing a shift towards global population ageing. Share of older persons has been growing progressively and it is projected to reach 22 per cent by 2050 worldwide. Above 80 percent of the world's elder people are projected to live in less developed countries by $2050(\mathrm{UN}, 2009)$. In India the elderly constitute 8 percent of the total population and it is likely to rise to $12 \%$ by $2026(\mathrm{CSO}$, 2011). Declining fertility rate and an increase in life expectancy are responsible for such demographic transitions. Life expectancy in India has gone up from 32 years at the time of Independence to 66.8 years in 2011(CIA, 2011). This demographic trend in relation to the children and adult population has a deep-rooted impact on the socio-cultural, economic political, psychological and health condition scenario of the elderly. Apart from the steady rise in the number of elderly, the traditional roles of these people have changed a lot due to such reasons as modernization, industrialization, urbanization, and westernization 'the four horsemen of the modern apocalypse.' Traditionally in India, the aged enjoyed honour respect and legitimate authority within the family and society but modern times have witnessed erosion in the traditional value system. All these issues in the film Dekha (2001) have been functionalized to make a better understanding of growing old. It may be an interdisciplinary gerontological

(c) AesthetixMS 2019. This Open Access article is published under a Creative Commons Attribution Non-Commercial 4.0 International License (http://creativecommons.org/licenses/by-nc/4.o/), which permits non-commercial re-use, distribution, and reproduction in any medium, provided the original work is properly cited. For citation use the DOI. For commercial re-use, please contact editor@rupkatha.com. 
collaboration. It is a contribution to fostering an interdisciplinary dialogue on how ageing as a lifelong process is understood and experienced. Gautam Ghosh raises critical awareness of gerontological issues in the presentation of older people on-screen in the popular genre of feature film which is an adaptation of the story by Sunil Ganguly, a canonical Bengali writer. It is generally acknowledged that society is influenced, often unknowingly, by the mass media. Film, a readily accessible popular entertainment medium has the potential to influence large number of viewers. James Monaco, the film theorist's comment in his famous book How to Read a Film: Movies Media and Beyond is relevant here:

There is a substantial difference between a description in words (or even in still photographs) of a person or event, and a cinematic record of the same. Because film can give us such a close approximation of reality, it can communicate a precise knowledge that written or spoken language seldom can. (Monaco, 2013:178).

So the filmic adaptation of the story has found better ground to be focused in the lives of some old characters particularly Sashibhusan Sanyal, the blind protagonist, his teacher, the retired professor of Scottish Church College, Nibaran, his assistant, Ashesh, his friend and classmate. It is a well-known fact that a growing number of feature length Bengali films (numerous Hollywood and Bollywood films also) are portraying the experience of older adulthood. Gautam Ghosh's Dekha is surely one of them. More importantly, the representation carries a positive message which has often been theoretically termed as 'active ageing', 'successful ageing' etc.

\section{Health Issues}

Increasing life expectancy has resulted in a larger proportion of the population to be in the age range where chronic and non-communicable diseases are the major cause of morbidity and mortality (WHO, 2002; Bhatt, Gadhvi, Sonaliya, Solanki and Nayak, 2011).Life expectancy has increased and will continue to increase. But the increased lifespan brings about different agerelated diseases. The poor health condition and infirmity, disability among the elderly as reflected in Gautam Ghosh's film Dekha lead the old people to confinement, reduced social contact, loneliness, depression, prevalence of morbidity etc.

\section{Frailty}

Sashibhusan Sanyal is an old character having infirmity, disability, and certain clinical characteristics that fulfil the criteria of being a frail person. Theoretically, frailty can be defined as a state of high vulnerability for adverse health outcomes, including disability, dependency, falls, a need for long-term cure and mortality (Fried et al., 2001). Frailty syndrome is defined as a series of multiple coexisting conditions-- weakness, immobility and poor tolerance to physiological and psychological stressors (Espinoza and Walston, 2005). From the very beginning of the film, he, as a blind dependent fellow draws our sympathy. He is glaucoma afflicted. The disabled person himself in his soliloquy makes confession of his difficulty. He says that his vision is getting more and more blurred day by day. In medical term it is called 'tunnel vision'. Two incidents of his life may be referred to here that would explain how he is entering the world of darkness. Driving his own car he is on his way home with a prostitute. More than once he is about to make accident. As life is at risk, the woman boldly tells him to stop. She would get down. It is not that Sashibhusan does not know driving or he is willingly doing it. The reason is his eye sight problem. Another example may be found in his vain attempt to pour wine into the glass. He, due to his dim vision, pours it on table. The harlot scolds him for making waste of wine. 
Frailty carries some clinical characteristics that impact upon the individual, family and friends. Our concept of frailty has emerged from the area of geriatric medicine. Evans (1997) noted this particular branch of medicine. Dr. Marjory Warren (1930) developed a system of classifying the degree of infirmity. It is a process of infirmity known as Comprehensive Geriatric Assessment (CGA). CGA measures individual's medical (co-morbidity, nutritional status), functional (basic ADLs i.e. Activities of Daily Life, gait \& balance), psychological (cognitive testing, mood and depression testing), social (e.g. informal needs, care resource eligibility), and environmental (home safety, transportation etc) assessments. Sashi's frailty has impacted his individual and family life and friends also. Frailty has brought about confinement in his own house, separation from his wife and daughter, and the friend circle. Sashi's chronic disease has deep-rooted association with his sense of morbidity. Sashibhusan Sanyal, the hero of the drama, is a victim to glaucoma, a chronic disease. Chronic health problems, by definition, are long term and noncurable. Implicit within the term is also, the notion of inevitable decline or deterioration. Medical intervention may (or may not) alleviate some, or all, of the associated symptoms and may halt (or slow down) the rate of decline. Glaucoma is one of those other problems like arthritis, dementia etc. This type of health hazard is integral, inevitable, natural and universal feature of old age. Such chronic diseases as glaucoma in case of Sashibhusan may prove to be fatal. It has made him completely blind. His blindness calls forth his dependence in some daily activities on others. Though Sashi is able to perform certain activities in his habituated world of daily life like eating, getting up and sitting, walking, telling time through tactile sensation (he often uses 'sense transference' or 'synesthesia') etc., but it cannot be denied that visual handicap has made this aged man dependent on others for his daily living.

\section{Sexual Dysfunction}

Although there is considerable individual variability in sexual activity with advancing age, most studies have demonstrated a steady and progressive decline in mature men and women (with women showing more significant declines than men).. This trend in aging was initially documented by Kinsey (Kinsey, Pomeroy and Martin, 1948) and reinforced by recent studies (Lindau et al., 2007). For example, the Baltimore Longitudinal Study of Aging showed that as men and women age, the frequency of sexual intercourse and sexual activity collectively decreased and, to a lesser extent, sexual interest also decreased (Martin, 1975). Besides aging, medical conditions can affect sexuality. Sexual problems can be due to physical limitations, side effect of medications or issues with self-image as a 'sick person.' Any illness that causes limited mobility, weakness can have a negative effect on sexual functioning. Some diseases like diabetes, hypertension, glaucoma, hyperlipidaemia have the clearest association with sexual dysfunction. Sashibhusan is an aged man afflicted with glaucoma. So it is no wonder that he is also affected by the normal aging process, as well as by his diseases. Added to it, it must be noted that Sashi's disease is chronic by nature. So most probably it requires regular medication which is another possible contributor to sexual dysfunction.

In addition to physiological aspects, there are the psychological factors applicable to Sashibhusan Sanyal. Research has proved that psychological problems are common contributors and should be screened, evaluated and treated. His alcohol abuse is a frequently encountered entity in his later life especially in conjunction with psychiatric illness. It is clear that the human mind has both excitatory and inhibitory effects on sexual arousal and response, and problems like anxiety and depression may interact with psychological causes of sexual dysfunction in aging adults. For example, the association between ED and depression is high with cause and effect probably moving in both directions, ED alone has been associated with depression rates as high as 50 
percent (Shab Singh et al., 1998). Sashi's life stressors like his complicated relationship with his wife and daughter, his affliction with glaucoma, sense of jeopardizasion, excessive alcohol consumption hamper his sexuality. He has still normal manly weakness for women but his physique is not supportive. This can be consolidated on the basis of his own confession to Gareema, agekar din hole tomake amar ghare nie jeye tultum. Tarpar nun ar golmarich diye tomer ai sharirta gyanta kheye nitam' (If it were earlier days, I would take you my home and eat up your physique alive with salt and pepper). In another scene, we find Sashi's love fantasy. Getting intoxicated by drinking ram (wine) Sarama says Amra ki karchi? (What are we doing?). Sashi says Amra prem karchi. Adim valabasar shabda shunte pachho? (We are doing love affair. Can't you hear the sound of primitive love?). Sashi calls Sarama near him, touches her face and says Tumi satyi baro hoye gacho (You have really grown up).That both have still infatuation for each other can be realized. Sarama comes back from office. Sashi stretched his hand to take cigar but Sarama holds his right hand with her left one to stop him. Sashi catches hold of her hand. It gives him tactile sensation. Sarama had once infatuation for Sashi. That past intimacy has not been lost altogether. What he is doing is nothing but the reflection of his dying or dead sexual desire. These happenings may prove Sashi's declining sexuality.

\section{Loneliness}

Sashibhusan Sanyal, the leadng character of the film Dekha perceives the undesirable experience of loneliness that comes from his inadequate relationship in terms of quality and quantity. From a cognitive and psychological perspective, his experience can be viewed as a subjective, emotional or affective one when he recognizes he lacks an intimate relationship with his family members particularly with his wife and daughter and feels that his social networks are deficient in some way. Weiss (1973) has identified two elements to loneliness-emotional loneliness, when people feel they don't have a close relationship with person like the spouse; and social loneliness when people lack friends or do not feel they belong to a community. In case of sashi in the cinema Dekha, the absence of intimate relationship with his spouse Reba Mallick is an example of subjective, emotional loneliness. Subjective loneliness also comes from his separation with his only daughter Sohini who has gone to America, now at Alaska, with her mother. That Sashibhusan has limited relationship in terms of its quantity and quality is beyond question. After his meeting with the tragic disaster, his social network has become deficient. Now he is a victim to social loneliness. He feels isolated and suffers from inadequacy of communication with others. A sense of being abandoned seizes him.

Further, De Jung Gierveld (1998) has demonstrated how loneliness may be conceptualized as a multidimensional construct when considered in terms of how individuals perceive, experience, and evaluate their isolation and inadequate communication with others. From this perspective, loneliness is seen in terms of three distinct elements: 'deprivation' i.e. when people recognize that they have feelings of emptiness or being abandoned; 'time' meaning whether people think loneliness can change or be remedied over time; and its emotional aspects, when loneliness involves feelings of sorrow, sadness, shame or guilt, for example. 'Time' factor here is crucial because his loneliness especially for his physical disability cannot be changed or remedied over time. From another aspect, Sashibhusan's loneliness emerges from his adjustment difficulty. His adjustment can only be understood in the context of what has led up to the present situation. His depression in the absence of his kins appears to reflect difficulty in coping with and adjusting to the new changed circumstances. 


\section{Depression}

The word depression that is regularly used in popular discourse may also be used here to describe the characteristic of Sashibhusan Sanyal. Over our life, all experience periods of sadness may make us feel 'depressed', but usually such episodes are short lived. Depression is different from sadness. It is broad and wide ranging. Mann (2001) suggests that there are three possible categorizations of depression. The first stage is defined by the possession of a variety of symptoms such as worry or sleeplessness. The second type is a greater number of symptoms, experienced at a more severe level and for greater duration. The third stage is the most extreme form of condition and is made by clinical diagnosis based upon severity. Which of the three categories does Sashibhusan belong to? On the basis of the experiences gathered from the movie, it is difficult to say. Harris (2003) reports that the predictors of depression among older men are disability and health conditions. Those with poor physical health are at considerably elevated risk of experiencing depression. Sashibhusan is suffering from the chronic disease glaucoma. He is a man of poor health due to his reckless indisciplined life style.

Poor health and depression are inextricably related. The adverse life events, difficulties, physical ill health, chronic medical conditions in Sashi's life are directly related to his depression. Some physical health conditions are said to have a specific association with depressive disorder. Chronic disease like glaucoma is positively one of these. Moreover, if Sashi is a diabetic, his disorder would be severer. Added to it, his emotional crises like loneliness have some contributions here. He may have some repentance for the reckless life he once used to lead. Another probable vital cause of his depression is his poetic career coming to a stop.

\section{Sense of Mortality and Morbidity}

The critic and theoretician Fries (1980, 2003) assumes a 'skewed' distribution of 'natural' mortality and argues that under 'ideal' conditions 95 per cent of deaths would occur between the ages of 77 and 95 years. We are, therefore, advancing rapidly towards this state whereby premature death has been largely eradicated and mortality in later life is as a result of the body 'wearing out' at the end of its 'natural lifespan' rather than because of disease per se. The cinema Dekha ends with the death of Sashibhusan. The pages of the diary and manuscripts are flying over to and fro; the empty chair is swinging. At which age he dies cannot be definitely told. But he was more than 6o. His teacher in his letter described him as a 'fair old man of 6o' (Prai sat bacharer sundar yubak). How much time has been passed till he has brought Gagan to him in Kolkata from his teacher cannot be told exactly. But it is true that a death after the age around 60 is not a premature death. Besides, there is no such view of Sashi's admission for treatment purpose. So it can be said that Sashi enjoys a normal lifespan and his normal death proves the truth and acceptability of Fries' theory.

But theoretically 'compression of mortality' means the expansion and increase of morbidity. This approach is termed by some the 'failure of success': lives would be longer but the extra years would be characterized by frailty, disability and ill health. According to Gruenberg (1977) the observed decline in mortality is the consequence of a decrease in fatality rates for many diseases rather than improvement in population health status. As a result of decreased death rates, there will be an increase in the morbidity of the population because, although more people will survive into old age, they will do so with much poorer health. Morbidity will be extended across a longer period. This scenario has been termed the 'Survival of the Unfittest'. Kramer (1980) termed this 'a pandemonic of mental disorder, chronic disorder and disability' while Olshansky (1990) and Carnes (1991) called it the 'expansion of morbidity hypotheses. 
We can appropriately contextualize Sashibhusan Sanyal on the basis of this theory of Gruenberg, Olshansky, Kramor, and Carnes. Sashibhusan is an ailed person suffering from chronic disease(s), a victim to some acute emotional crises, and a witness to some stressful experiences of life. He has enjoyed a prolonged life. At the same time, he was subject to morbidity and the sense of mortality. Almost in the beginning of the movie, we see him engrossed in listening to an old Bengali song Amar jabar bela pichu dake/Bhorer alo megher phake/ Pichu dake (In time of my starting journey, somebody calls back from the hollows of the clouds in the morning). Reaching towards the ending part of life, Sashibhusan is thinking about death. Here jabar bela (time of journey) may refer to the time of his beginning voyage to life beyond death. The song brings about the sense of mortality. The interpretation may go otherwise. The song tells him of his journey towards the future and his past colourful days call him back. Sashibhusan is nostalgic and feels unhappy collecting his lost colourful days. Sashi pains to evaluate the present in terms of his past. Sashibhusan is an established poet, philosopher. He must know that life and death are woven in a string. None can escape death. Then is it that Sashi is morbid not only for his sense of mortality but something else? Perhaps it can be that Sashi is feeling guilty or remorse. We know well that his reckless lifestyle contributes a lot to his divorce from his wife. If he could show restraint a bit his life would go otherwise. That he is feeling guilty can be understood from his interest in listening to another song by Rajani Kantha Sen Tumi nirmalo karo mangalo kare malino marmot muchaye (Make it pure washing malignance by your benign hands). Perhaps Sashibhusan intends to surrender to God and to make his life purer at the touch of his merciful hand. The film ends with the mystic song of Gagan Monore krishi kaj janona (O mind! You don't know cultivation). Gagan's song reminds Sashi of the barrenness of life. Both Sashi and Gareema are drawing attention to Gagan's song. Sashi's creative composition is being interrupted by his thought of infertility of life. He becomes morbid. The last poem that Sashibhusan writes:

Ekdin keu ase balbe/Tomer buker sindhukta akendin khola hoini/ Ami koyek jhalak bidyut anachi/ Ekdin keu ase balbe/ Tomer ghar anekdin dhoa mocha hoini / Ami ekta nadi anechi/ Ekdin keu ase amar hat dharbe/ Pathale nebe jaber aghe [...]

(Oneday someone will come and say/ Chest of your chaste has not been opened for many days/Give it some light/ I have brought some flashes of light/ Oneday someone will come and say/ Your room's left damp for long/ I have brought a river to freshen it/ Oneday someone will grasp my hand/ Before getting down to the underworld...)

Gareema seeks Sashi's permission for the publication of his earlier poems. She recites a poem of nearly 17 years ago Swapner moto ekti bindu dulche andhokare (A dot of light swinging in darkness, surrounded by tranquil nostalgia). Sashibhusan makes a significant comment regarding the subject of the poem which bears a deeper connotation. He says Tokhan ami andhokarer mane bujhtamna (At that time I didn't know the meaning of darkness). This andhokar (darkness) indicates not only his blindness but the inward gloom and frustration. The reference of the underworld pathal (hell) suggests his feelings of mortality and morbidity.

\section{Social Exclusion}

Older people particularly those who are frail or disabled need care and services i.e. assistance in a supportive manner. For those older people who need care in later life, there are two major resource domains available in theory at least, to meet these needs: the formal services provided by statutory or voluntary agencies and informal networks (Christina Victor, 2005).Gautam Ghosh's film Dekha attests no direct reference to the formal care but may bear some circumstantial evidences. We know Sashibhusan was a professor of literature in Scottish Church College. He, as a disabled person, might enjoy some relaxations relating to leave, tax etc. under State and central 
Governments administered regulations. In informal sector which is referred to as the 'natural support system' by Baker (1977), the source of care or natural helpers are family members, kin, friends, neighbours, natural helpers. The network of kin and non-kin relationship provides many of the resources with which older people turn when faced with the vicissitudes of life such as illness, infirmity, frailty, emotional distress and financial or material problems. The family and wider social network clearly play an important role in the lives of the older people. Maintaining contact with other people is crucial in maintaining a reasonable quality of life (QOL). Researchers have found that positive social interactions between older people and their family members, relatives, friends, and the neighbours protect against developing difficulties with physical functions in later life (Berkman and Syme, 1979; Cape and Gybson, 1994; Seeman, 2001). Other studies have shown that being part of an extensive social network has a protective effect on elder's health (Edelbrock, 1990; Liang, 1992; Revicki and Michell, 1990). But unfortunately Sashi's social network has been shrinked after the tragic disaster of his life. He has no regular contact with his friends except Ashesh, his classmate. In his family life, after his divorce with Reba Mallick, his spouse, he has lost the opportunity of having familial care. His only child Sohini has also departed with her. Naturally in family life, he lacks the chance of getting informal care service. For maintaining quality of life (QOL) Sashi, as an infirmed person would require informal support networks and their complementary partnership may be promoted in integrating formal and informal care sectors to bring about happiness and positive well-being. Sashi has no extended family or large kinship network to render such care. His support network is limited to a very few persons only. Moreover, this support network is not from his kins but non-kins. Such smallness of this informal network is a matter of social concern. In the movie Sarama acts as a principal nonkin or non-family caregiver. Besides Sarama, we may also refer to a number of persons like Nibaran, Suman (Sarama's son), Reema Dutta, the youngest journalist, Ashesh, Sashi's friend and classmate and lastly Sarama's parents.

\section{Constitutional Provision and Policy Initiatives}

Policy making is so relevant and important relating to the study of ageing as only it can counter the old-age problems. On the basis of the legal provision in Indian Constitution (Entry 24 in List III of Schedule VII, Item 9 of the State List, Items 20, 23, and 24 of Concurrent List, Article 41 of Directive Principles of State Policy, Section 125-128 of Criminal Procedure Code 1973 etc.) many Government policies have been adopted. The World Assembly on ageing, 1982 endorsed by United Nations General Assembly \& Madrid International Plan of Action on Ageing (MIPPA), 2002 are the world assemblies that gave guiding thinking and formulation of policies and programmes on ageing. The Ministry of Social Justice and Empowerment has National Policy for Older Persons (NPOP), 1999, and National Council for Older Persons (NCOP), 1999, which is the highest body to advise in the formulation and implementation of policy and programme. The National Policy for Senior Citizens (WPSC-2011) brings the oldest old under the Indira Gandhi National Old Age Pension Scheme. Ministry of Health and Family Welfare has formulated National Programme for the Health Care of Elderly (NPHCE). All these policies have been adopted to promote old people as valuable recourses and to monitor their social and economic security, health care services and insurance, pension etc.

Adoption of different policies is a ray of hope but their enactment on the grassroots level reality is a more difficult task. Besides, the existing policies are not adequate enough. The prevailing policies require changes keeping pace with the needs of the present society. This change should be on the basis of the continuous research on ageing. More inclusive programmes may be introduced that can engage the elderly in the development process. Different welfare projects may 
be launched with adequate infrastructure and human resources giving prime focus on the disabled and chronically ill elderly. Incorporation of the innovative health insurance scheme, institutional community-based care programme may promote the situation. Following many foreign countries like Japan and Germany mandatory care insurance may be introduced for social security of the senior citizens.

\section{Suggestions and Conclusion}

On the basis of the discussion so far it may be said that there is an emerging necessity on part of the Government to initiate holistic policies and programmes to promote positive ageing. Positive ageing and the related terms like 'productive ageing', 'healthy ageing', 'successful ageing' indicate a paradigm shift, a non-traditional approach. It suggests positive involvement of the senior citizens in the various developmental schemes. This positive imaging of the elderly in gerontology relates to the activity theory (in opposition to disengagement theory that argues for disengagement and transfer of power from the old to the young) which is a prescriptive view of ageing arguing for activity, involvement that leads to successful ageing. It is positive ageing which can combat the ageism( assumption, discrimination, fears about growing older), which is based on stereotypes, myths about ageing, and language that conjures up negative images of older adults as non-productive, unable to think clearly and quickly and having a negative outlook to life. Productive ageing promotes independence, participation, dignity, care and active engagement with life. Research is quite clear that an emphasis on positive ageing, including social connectedness, meaningful participation, and involvement among older adults ensures a longer and healthier life (Kawachi, Kennedy \& Glass, 1999; Putnam, 2000; Putnam and Feldstein, 2003). In this film Dekha, Sarama's father in his letter to his student Sashibhusan Sanyal quotes the remark of the litterateur Sanjib Chandra regarding aging, Akkhuni ami driddha kajai prai briddhake sundor dekhi (At present I am old, so I look upon almost all the aged as beautiful). To a great man (unnamed here), manushyu briddha na haile sundor haina (Men do not become fair unless they be old). The old retired professor's thought and its expression attest the optimistic attitude towards aging. His successful positive ageing efforts can be traced in his concerns on India partition, Babri masjid, role of the Bengali intellectuals etc. His reference to the book Nimnabarger Itihas (Source book Subaltern Studies) indicates the continuation of his practice of reading. Sashibhusan Sanyal has resumed his poetic life once again at the inspiration of Sarama and Gareema Dutta. Gareema acts as his writer. The traumatic experience of life has made him more prudent. Sashi restarts his career. He writes a new poem Ekdin keu ase balbe [...] (One day someone will come and say...).Sashibhusan's poem carries an inspiring message to all older adults and sundry. He puts forth a strong fight against all the hostilities in the autumn of life. As these adversities are the true relevant picture of our present society, the fight of Sashi and other old characters' in the movie will surely promote our society to a better and a more glorious future.

\section{Note}

Translated from Bengali by the first author

\section{References}

Baker F (1977) The interface between professional and natural support systems. Clinical Social Work Journal 5: 139-48. 
Bengtson VL, Jonson ML \& Putney NM eds (2007) Cambridge Handbook of Age and Ageing. Cambridge University Press.

Blackburn JA \& Dulmus CN eds (2007) Handbook of Gerontology: Evidence- Based Approaches to Theory, Practice, and Policy. John Wiley \& Sons Inc.

Bond J \& Coleman P (1990) Ageing in Society: An Introduction to Social Gerontology. New Delhi: Sage Publications.

De Jung G (1998) A Review of loneliness concept and definitions, determinants and consequences. Reviews in Clinical Gerontology 8:73-80.

Dix A (2010) Beginning Film Studies. Viva Books Pvt. Ltd.

Espinoza S. and Watson JD (2005) Frailty in Older Adults: Insights and Interventions. Cleveland Clinic Journal of Medicine 72 (12): 1105-1112.

Evans, J.G. (1997) Geriatric medicine: a brief history. British Medicinal Journal. 315:1075-1077.

Fried LP et.al (2001) Frailty in older adults: evidence for a phenotype. The Journals of Gerontology Series A: Biological Sciences and Medical Sciences 56: M146-M157.

Fries JF (1980) Ageing natural death, and the compression of morbidity. New England Medical journal 303:130-135.

Fries JF (2003) Measuring and monitoring success in compressing morbidity. Annals of Internal Medicine 139(5):455-463.

Gruenberg EM (1977) The failures of success. Millbank Memorial foundation Quarterly 55: 3-24.

Hassis T et al. (2000) Predictors of Depressive Symptoms in Older People Age and ageing 32(5):510-518.

Jamuna D (2000) Ageing in India: some key issues. Ageing International 25(4):16-31.

Jary D \& Jary J (1991) The HarperCollins Dictionary of Sociology. New York: Harperperennial.

Kinsey AC, Martin CE \& Pomeroy WB (1948) Sexual Behaviour in the Human Male. Philodelphia: W.B. Saunders.

Kramer $M$ (1980) The rising pandemic of mental disorders and associated chronic diseases and disabilities. Acta Psychiatrica.62 (285): 282-297.

Lamb S (2012) Aging and the Indian Diaspora: Cosmopolitan Families in India and Abroad. Orient Blackswan Pvt. Ltd.

Liang J (1992) Social support among the aged in Wuhan, China. Asia Pacific Population Journal 7(3):33-62.

Lindau ST et al. (2007) A Study of sexuality and health among older adults in the United States. New England Journal of Medicine 357(8): 62-74.

Mann A (2000) Depression in the elderly Maturitas. 38 (1): 53-58.

Monaco J (2009) How to Read a Film: Movies Media and Beyond. New York: Oxford University Press.

Olshansky SJ, Carnes B \& Cassel C (1990) In search of Methuselah: estimating the upper limits to human longevity. Science 250: 634-40.

Olshansky SJ et al. (1991) Grading off longer life for worsening health: the expansion of morbidity hypothesis. Journal of Ageing and Health 312:194-216.

Panruti R V Liebig, Phoebe S \& Duvvuru J (2015) Gerontology in India. The Gerontologist 55(6):894-900

Philips J, Ajrouch K \& Hillcoat-Nalletamby S (2010) Key Concepts in Social Gerontology. New Delhi: Sage Publications. 
Philliston C (2007) The elected and the excluded; sociological perspectives on the experience of place and community in old Age. Ageing \& Society 27: 321-342.

Sellersten IA. \& Angel J (2011) Handbook of Sociology and Social Research. Springer.

Snyder MH (2011) Analysing Literature-to-Film Adaptations: A Novelist's Exploration and Guide. New York: The Continuum International Publishing Group.

Stuart- Hamilton I (2011) An Introduction to Gerontology. Cambridge University Press.

Townsend P (1957) The Family Life of Old People. London: Routledge and Kegal Paul.

Victor C (2005) The Social Context of Aging: A Text Book of Gerontology. London/ New York: Routeledge.

Weiss RS (1973) Loneliness: The Experience of Emotional and Social Isolation. Cambridge: The MIT Press Reader. 